\title{
Encouraging customers to pay less for mobile telecommunication services
}

Received: 6th February, 2002
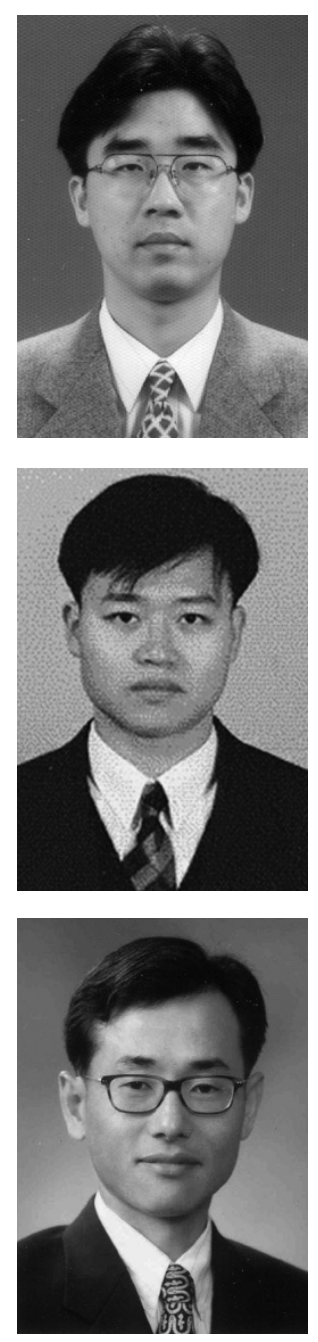

Byung-Do Kim

Seoul National University, College of Business Administration, 56-1 Shinlim-dong, Kwanak-ku, Seoul, 151-742, Korea.

Tel: 82-2-880-8258; Fax: 82-2-878-3154; e-mail: bxk@plaza.snu.ac.kr

\section{Young-Hyuck Joo}

is Research Professor of Marketing at the School of Business Administration, Sungkyunkwan University, Korea. He received his MBA and PhD from Seoul National University, Korea. His current research interests include consumer choice modelling, database marketing, CRM and Internet marketing.

\section{Jong-Kun Jun}

is Senior Lecturer in Internet Business at the College of Commerce and Economics, Dong-Eui University, Korea. He received his MBA and PhD from Seoul National University, Korea. His current research interests include Internet shopping behaviour, e-business models, database marketing and retailing.

\section{Byung-Do Kim}

is Associate Professor of Marketing at the School of Business Administration, Seoul National University, Korea. He was previously on the faculty of Carnegie Mellon University, Pittsburgh, USA. His current research interests include various econometric and statistical modelling issues on consumer choice behaviour, e-commerce, reward programmes and database marketing. His previous research has appeared in Journal of Business \& Economic Statistics, Journal of Interactive Marketing, Journal of Marketing Research, Journal of Retailing, Marketing Letters and Marketing Science, among other journals.

Abstract This paper introduces a database marketing strategy to help customers pay less for mobile telecommunication services. Many customers are subscribing to the wrong calling plans, and pay more because it is difficult for them to forecast their future calling patterns and to evaluate the complicated pricing schedules offered by firms. By encouraging those customers to switch calling plans, a company is shown how to increase its long-term profits through increased retention rates although it will lose its short-term profits.

Based on the authors' research of 10,000 randomly-selected customers from a mobile telecom company, it was discovered that customers with the correct calling plans have higher retention rates when compared to customers with the wrong calling plans. About 40 per cent of customers are subscribing to the wrong calling plans. Additionally, not all customers with the wrong calling plans should be encouraged to switch to the optimal calling plans. From the authors' empirical application, this marketing strategy is shown to be worth implementing for approximately 20 per cent of those customers with the wrong calling plans.

\section{INTRODUCTION}

A major issue that managers in various industries continue to emphasise to their workforce is increasing the retention rates of their customers. As an industry enters the mature stage of its product life cycle, competition increases and it is more costly for firms to acquire new customers. Firms are recognising that retaining their current customers is more important and less costly than acquiring new customers. Marketing researchers 
have shown that a firm's profit is closely related to its brand loyalty or customer retention rate. ${ }^{1-3}$ Loyal customers are profitable because they are likely to be frequent users and tend to be less price sensitive. Moreover, since they are satisfied with the brand, they often recommend the brand to other customers.

The main focus of this paper is to evaluate a marketing strategy to help customers pay less for mobile telecommunication services. Most mobile telecom companies provide several complicated calling plans and provide options for consumers to choose between. Often, it is not an easy task for customers to forecast their calling patterns and select the correct plan. Customers are not always rational as many economists assume. Many customers in the mobile telecom industry pay more partially because they choose the wrong calling plans. Customers with the wrong calling plan are likely to switch to competitors with lower calling rates. Keaveney provided the insight that pricing is the key reason for a customer to switch to competitors. ${ }^{4}$ Customers switch because of dissatisfaction with high price, price increases, unfair pricing practices, deceptive pricing practices and so on.

A mobile telecom company can increase short-term profits by allowing customers to subscribe to more expensive calling plans and pay more. Moreover, it should analyse the historical calling pattern of each customer to identify customers who can save on their monthly telephone charge by switching calling plans. Additionally, it should appoint a customer service representative to target customers and encourage them to consider changing their calling plans. What is the benefit? The marketing strategy will increase customer satisfaction with the new plans and increase customer retention rates; thereby benefiting the mobile telecom company.

The concept of maximising customer lifetime value indicates that not all customers should necessarily be encouraged to switch to their optimal calling plans. The firm should carefully evaluate the benefits of the increased retention rates resulting from the customers switching into the better calling plan, and determine if these benefits are large enough to cover marketing costs and short-term profit losses. Based on the data from 10,000 randomly-selected customers from a mobile telecom company, the authors show that customers with the best calling plans have higher retention rates than customers with the wrong calling plans. Around 40 per cent of customers are subscribing to the wrong calling plans. The company could increase its long-term profits - hence, should encourage them to switch into the other calling plans - for a minimum of 20 per cent of those customers with the wrong calling plans.

The remainder of this paper is organised as follows. The next section explains why the firm should help customers to select the right pricing schedules. Introducing a simple construct of customer lifetime value, the authors show that the firm could increase its long-term profits due to the decreased attrition rates by encouraging customers to switch into the right calling plans, even though it will lose its short-term profits. The next section describes the data for the empirical application. The following section describes the econometric model to analyse the data and present the estimation results. The authors adopt the hazard function model that is appropriate for analysing the duration data. All the parameters are shown to be statistically significant and intuitively make sense. The penultimate 
section discusses the profit implications of helping customers to select the optimal calling plans based on the estimation results. The authors also explain why those customers have initially chosen the wrong calling plans. Finally, the authors discuss the limitations of the model and future research directions and reach their conclusions.

\section{HELPING CUSTOMERS SELECT THE RIGHT CALLING PLAN}

Firms can maximise profits by maximising lifetime values of their current and potential customers. Any marketing strategies and tactics should be evaluated in terms of their impact on customers' lifetime values. For example, a temporary price discount may significantly increase unit sales and result in increased short-term profits. Such discounts, however, often encourage customers to believe that price discounts will continue in the future and put them off buying products at the regular price. This is bad marketing strategy because it decreases customers' lifetime values.

The mobile telecommunication company will definitely lose short-term profits by helping customers select the correct calling plans. In fact, the company could increase profits if those customers were to keep the wrong plans. Using its own money, however, the company should analyse each customer's calling pattern to identify what savings they could make on their monthly telephone charges by changing their plan. The company should appoint someone in its calling centre to call target customers and encourage them to change their calling plans. This marketing strategy can only be justified if it increases the satisfaction of those changing their calling plan and, possibly, customer retention rates.

Consider a customer who selects the wrong calling plan and currently pays $p_{c}$ for her monthly telephone charge. Her retention probability is $r_{c}$. In order to increase the retention probability of this customer, the company spends marketing and database-related expenditures $m$ per customer and helps her to switch to the better calling plan. The better calling plan requires her to pay $p_{o}\left(<p_{c}\right)$ and save $p_{c}-p_{o}$ a month. The resulting retention probability with her new and improved calling plan becomes $r_{o}\left(>r_{c}\right)$. The customer should be contacted for discussion on alternative calling plans if her lifetime value with the right calling plan is larger than the lifetime value with the wrong (current) calling plan. It can be written more formally as

$$
\begin{aligned}
p_{0} & \sum_{t=0}^{\infty}\left(\frac{r_{0}}{1+d}\right)^{t}-m=\frac{p_{0}(1+d)}{1+d-r_{o}} \\
& -m>p_{c} \sum_{t=0}^{\infty}\left(\frac{r_{c}}{1+d}\right)^{t}=\frac{p_{c}(1+d)}{1+d-r_{c}}
\end{aligned}
$$

where $d$ is the (monthly) discount rate. In order to make this marketing strategy justifiable, the increase of retention probability by switching into the right calling plan should be large enough to cover marketing costs $m$ and the profit loss due to the reduced telephone payment $p_{c}-p_{o}$.

\section{DATA}

In order to see the difference in retention rates between consumers with the correct calling plans and consumers with the wrong calling plans, the data supplied by ABC Mobile

Telecommunication Company were analysed. The database consists of 10,000 randomly-selected customers with their demographic and purchase behavioural variables. There are four types of calling plans. One of them is targeted to a specific group of customers, and has a 
Table 1: Summary statistics

\begin{tabular}{llrr}
\hline Variables & Descriptions & Mean & $\begin{array}{r}\text { Standard } \\
\text { deviation }\end{array}$ \\
\hline DURATION & Number of days using mobile service of this company & 714.74 & 538.52 \\
CHURN & O if current customer; 1 if not current customer & 0.40 & 0.49 \\
DUTY & Duration of mandatory service & 0.78 & 0.78 \\
SEX & O if female; 1 if male & 0.80 & 0.40 \\
AGE & Age of the customer at the time of data collection & 36.73 & 9.94 \\
PAYMENT & (Average) monthly mobile charge & 30.95 & 17.45 \\
MPBRAND & 1 if the brand of the mobile phone is A; 0 otherwise & 0.63 & 0.48 \\
MPCHANGE & Frequency of changing the mobile phone & 1.51 & 1.20 \\
SAVING & Payment difference between selecting the right and wrong & & 3.48 \\
& calling plan & & \\
\hline
\end{tabular}

very complicated pricing schedule. This type of plan is also not comparable to the other three. Therefore, the authors limited their attention to only three types of calling plans and customers choosing these three. They also eliminated some customers with missing demographic and/or purchase behavioural variables. The authors analysed data for the remaining 6,753 customers.

A list of the demographic and purchase behavioural variables used in the econometric model with their summary statistics is given in Table 1 . As discussed in the next section, the dependent variable of the model is DURATION which measures the number of days using the mobile service of $\mathrm{ABC}$ mobile telecommunication company. For current customers, it is the number of days from the service starting date to the current date. It is measured as the number of days from the service starting date to the ending date for previous customers. DURATION is widely spread among customers with a mean of about two years.

The variable CHURN is the indicator variable coded as 0 if the customer is still alive at the time of data collection and 1 if she is not a current customer. The samples consist of 40 per cent previous customers and 60 per cent current customers.
There are two demographic variables used in the analysis, SEX and AGE. The variable SEX is the male indicator variable coded as 1 if the customer is male, and 0 if the customer is female. Eighty per cent of the sampled customers are males. The variable AGE measures the age of the customer at the time of data collection. With a mean of 37 , ages of the sampled customers ranged from 16 to 78 years old.

Reflecting a popular marketing strategy in the mobile telecommunication industry, the variable DUTY is an interesting independent variable measuring the duration of mandatory service contract. In order to increase the number of new customers in a short period of time, mobile telecom companies frequently promote their service with heavily discounted or free mobile phones. Customers get the free mobile phone by subscribing to the new mobile service. In return, they are required to stay in the same mobile company for the designated period of time on the service contract. They should pay the penalty fee if they discontinue the service during the contracted period. Therefore, customers who get the free promotional phone tend to have longer retention probability. A mobile telecom company initially spends large amounts on free phones and 
expects to reap additional profits over the long term. The variable DUTY measures the duration of this mandatory usage contract (measured in years).

The variable PAYMENT represents the mobile charges (measured in dollars) customers pay for a month. For each customer, this variable is measured by averaging monthly mobile charges over the previous six months from the time of data collection. The average customer in the sample is shown to pay $\$ 30.95$ per month.

The variable MPBRAND is an indicator variable coded as 1 if the mobile phone owned by the customer is Brand $\mathrm{A}$ and coded as 0 for other brands. Brand $A$ is the top brand owned by 63 per cent of the sampled customers. On the other hand, the variable MPCHANGE measures the frequency with which the customer changes mobile phone during the observation period.

The variable SAVING is the key variable of interest. It is the difference in payment from using the right calling plan over the wrong calling plan. Therefore, it is the dollar savings recognised by switching to the right calling plan. Table 1 shows that the average dollar savings in the sampled customers is $\$ 1.51$. The value may look less than expected. Around 60 per cent of sampled customers, however, had already selected the right calling plan, and their values for the variable SAVING are obviously zero. The average dollar saving goes up to $\$ 3.77$, if only the 40 per cent of the remaining customers who selected the wrong calling plan are considered.

The variable SAVING is not actually supplied by the ABC mobile telecom company but inferred by a series of approximations and data manipulations. The variable SAVING could have been measured directly and more accurately if there had been more detailed information on each call - such as the time of each call, its duration, the phone number of the receiver. Unfortunately, the information on individual calls is not available. Instead, it is known how many hours each customer calls each month during the observation period. So the study first describes the pricing schedule of three calling plans to approximate the variable SAVING.

Each calling plan has a two-part tariff as a basic pricing structure. For example, for the calling plan option 'Economy,' customers should pay the fixed charge of $\$ 7.69$ and the additional marginal fee of $\$ 10.07$ per hour. This marginal fee actually changes depending on when the call is made and which phone number the call is connected to. The average value for the marginal fee is used here because the information on individual calls is not available. The pricing schedules of three calling plans in the compact functional form can be expressed as:

Type I

(Economy): $Y=7.69+10.07 X$

Type II

(General): $\quad Y=13.85+5.97 X$

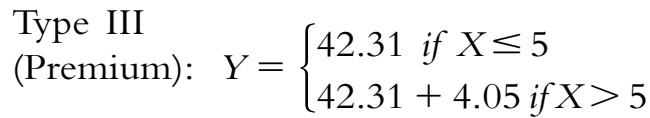

In the above equations, $X$ is the duration of calls per month measured in hours and $Y$ is the monthly phone charge measured in US dollars. Light callers can minimise their mobile phone charge by subscribing to the Type I calling plan while the Type III calling plan is the optimal plan for heavy callers. This can be seen more clearly in Figure 1. It shows that the Type I calling plan is the best for customers who call less than 1.5 hours per month. Similarly, customers who use the phone for between 1.5 and 4.8 hours per month should subscribe to 


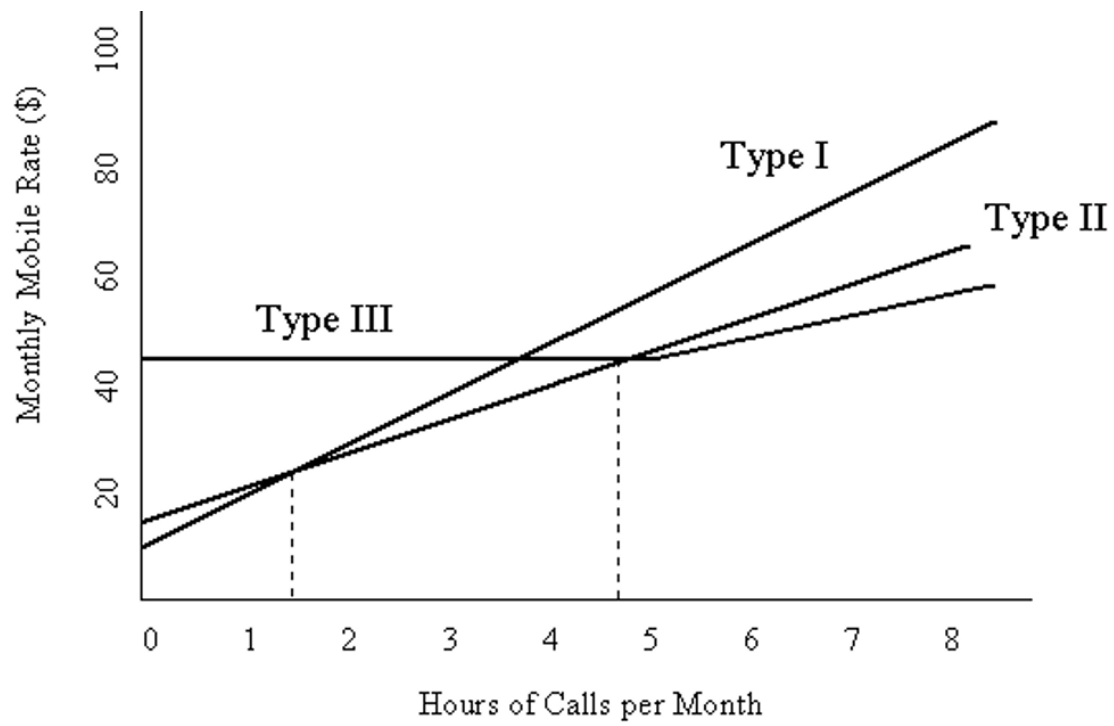

Figure 1: Pricing schedules of three calling plans for $A B C$ mobile telecom

Type II and customers over 4.8 hours should select Type III.

Based on these equations of two-part tariffs, it is now possible to tell which calling option is the best for a particular customer. The analysis shows that about 40 per cent of the sampled customers (ie 2,704 out of 6,753 customers) are subscribing to the wrong calling plans. In addition, the variable SAVING for each customer is approximated by the difference in the current mobile rate with the wrong calling plan compared to the expected mobile rate given the optimal calling plan.

\section{ESTIMATION RESULTS}

The dependent variable (DURATION) of the econometric model is the number of days subscribing to the ABC mobile service. The hazard function model that is appropriate for analysing this type of duration data is adopted. Hazard function models are increasingly recognised in the marketing literature. ${ }^{5,6}$ The advantage of the hazard function model is twofold: the ability to incorporate right-censored observations and the ability to allow for time-varying covariates. Remember that the variable DURATION is right-censored for all of the current customers.

The number of days subscribing to the ABC mobile service or the duration of being a customer $(T)$ is denoted by a random variable with probability density function $f(t)$, cumulative density function $F(t)$, survivor function $S(t)=1-F(t)$, and hazard function $h(t)=f(t) / F(t)$. The relationship among these four functions can be deduced from the familiar relationship:

$$
\begin{aligned}
f(t) & =h(t) S(t) \\
& =h(t) \exp \left[-\int_{0}^{t} h(u) d u\right]
\end{aligned}
$$

For mathematical convenience, the hazard function $h(t)$ instead of the probability density function $f(t)$ is modelled. In this application the parametric approach is adopted where the hazard function $h(t)$ is assumed to be exponential, Weibull, log-logistic, log-normal or generalised gamma. ${ }^{7,8}$ From now on attention is limited to the log-logistic hazard because only its estimation results are reported. The 
log-logistic hazard function for customer $i$ can be written as:

$$
h_{i}(t)=\lambda p(\lambda t)^{p-1} /\left[1+(\lambda t)^{p}\right]
$$

Hence, its survival function $S_{i}(t)$ is $1 /\left[1+(\lambda t)^{p}\right]$. It is fairly straightforward to incorporate covariates by letting $\lambda_{i}=\exp \left[\beta^{\prime} X_{i}\right]$ where $X_{i}$ is the set of covariates for customer $i$.

The covariates in the model consist of seven variables mentioned above: DUTY, SEX, AGE, PAYMENT, HPBRAND, HPCHANGE and SAVING. Then the second component of the hazard function is:

$$
\begin{aligned}
\lambda_{i}= & \exp \left[\beta_{1} \text { DUTY }_{i}+\beta_{2} \text { SEX }_{i}\right. \\
& +\beta_{3} \text { AGE }_{i}+\beta_{4} \text { PAYMENT }_{i} \\
& +\beta_{5} \text { MPBRAND }_{i} \\
& +\beta_{6} \text { MPCHANGE }_{i} \\
& \left.+\beta_{7} \text { SAVING }_{i}\right]
\end{aligned}
$$

The model parameters are now estimated by maximising the sample likelihood function. The estimation results do not change much across five different parametric distributions. The estimation results for the log-logistic baseline hazard are reported because its Bayesian Information Criterion (BIC) is the largest. ${ }^{9}$

Table 2 shows the estimation results with the specification of log-logistic hazard. All the coefficients are statistically significant at $p=0.05$. The estimated coefficient of -0.134 for SEX indicates that the attrition rate is lower for male. The relative hazard is a useful concept to measure the impact of covariates on the hazard function. It is given by $100 \times\left[\exp \left(\boldsymbol{\beta}_{k}\right)-1\right]$ and measures the percentage change in the hazard if the $k$-th covariate is incremental by one unit. Hence, the attrition rate for males is $\mathbf{1 2 . 5}$ per cent lower than for females.

The negative value for the AGE coefficient indicates that older customers
Table 2: Parameter estimates for the log-logistic baseline hazard

\begin{tabular}{ll}
\hline Variables & Parameter estimates \\
\hline Intercept & $-2.135(0.055)$ \\
DUTY & $-0.161(0.017)$ \\
SEX & $-0.134(0.027)$ \\
AGE & $-0.024(0.001)$ \\
PAYMENT & $-0.006(0.001)$ \\
HPBRAND & $-0.129(0.022)$ \\
HPCHANGE & $-0.121(0.003)$ \\
SAVING & $0.015(0.003)$ \\
$p$ & $0.394(0.006)$ \\
Log-likelihood & $-4,373.8$ \\
$N$ & 6,753 \\
\hline
\end{tabular}

Note: Standard errors in parentheses

tend to stay longer. Similarly, all four variables (DUTY, PAYMENT, HPBRAND and HPCHANGE) negatively influence the attrition rate. If a customer signs a mandatory usage contract in return for a free or heavily discounted mobile phone, they are likely to have lower attrition rates. Heavy users are high-value customers not only because they spend more per month but also they tend to have a lower attrition rate. Customers who own the Brand A mobile phone (that is the top brand) tend to have a lower attrition rate. And those customers who change their mobile phone more frequently are likely to have a lower attrition rate.

The variable SAVING is the key variable of interest. The estimated coefficient of 0.015 indicates that customers with the wrong calling plans have higher attrition rates, or customers will stay longer if they select the right calling plans. The company has an incentive to help customers with the wrong calling plans to switch into the optimal calling plans and save monthly bills. Its relative hazard rate of 1.5 shows that attrition rates for customers overpaying $\$ 1$ per month are 1.5 per cent higher than for customers selecting the optimal calling plans. 


\section{PROFIT IMPLICATIONS OF ENCOURAGING CUSTOMERS TO PAY LESS}

Based on the estimation results here, the implications for the marketing strategy of encouraging customers to pay less are illustrated. Equation (1) is slightly modified since the hazard function has been employed for the econometric model. In the hazard function model the dependent variable is the duration of subscribing to the $\mathrm{ABC}$ mobile service measured in continuous time. (Equation (1) is expressed in retention rates with discrete time intervals.) Rewriting the equation (1) in continuous duration time:

$$
\begin{aligned}
& \int_{0}^{\infty} p_{o} T_{o} f\left(T_{o}\right) e^{-\rho T_{o}} d T_{o}-m> \\
& \int_{0}^{\infty} p_{c} T_{c} f\left(T_{c}\right) e^{-\rho T_{c}} d T_{c}
\end{aligned}
$$

where $T_{0}$ is the duration of subscribing to the mobile service given that the customer selects the optimal calling plan, $T_{c}$ is the corresponding duration given that the customer maintains the current calling plan, and $\rho$ is the discount rate. If $m=\rho=0$ is assumed, equation (5) will be simplified as $p_{o} E\left(T_{o}\right)>p_{c} E\left(T_{c}\right)$.

The median duration for $\mathrm{E}(\cdot)$ is used because it is a much-preferred measure of central tendency for censored survival data. Allison noted that the mean is biased downward when there are censoring times greater than the largest event time. ${ }^{11}$ And the upper tail of the distribution is poorly estimated when a substantial number of the cases are censored. In the log-logistic hazard, the median duration is $1 / \lambda_{i}=\exp \left[-\beta^{\prime} X_{i}\right]$. Hence $E\left(T_{c}\right)$ is equal to the median duration with the current value of SAVING while $E\left(T_{0}\right)$ is equal to the median duration with SAVING $=0$. Obviously, $E\left(T_{c}\right)$ becomes identical to $E\left(T_{0}\right)$ when the customer has already selected the right calling plan

$($ SAVING $=0)$.

1,602 out of 4,051 current customers are identified as subscribing to the wrong calling plan. $\Delta=p_{o} E\left(T_{o}\right)-p_{c} E\left(T_{c}\right)$ for each of those 1,602 current customers with the wrong calling plan is computed. $\Delta$ is the additional profit from persuading the customer to switch into the optimal calling plan. $\Delta$ is greater than 0 for 318 out of 1,602 customers. That is, those 318 customers are the target customers for the company to switch into the optimal calling plan. The resulting expected total profits are $\$ 125,309$ with a mean of $\$ 390$.

In order to understand the purchase behaviour of 318 target customers in greater detail, their currently selected calling plans in Table 3 are looked at. Theoretically there will be six types of customers with the wrong calling plans (eg current calling plan of 'General' with the optimal calling plan of 'Premium'). In the sampled data, however, there are only three types among 1,602 customers identified as subscribing to the wrong calling plan. About 90 per cent of customers with the wrong calling plan are currently subscribing to the 'General' plan. This is partially because the 'General' calling plan is the default. Many customers may have difficulty in understanding the pricing schedules of each calling plan or forecasting their future mobile demand. They tend to select the most popular calling option, the 'General' plan. Or some of them virtually give up the selection and the default, the 'General' plan, is assigned.

Let us now focus on 1,450 customers who are subscribing to the wrong 'General' calling plan. Among those, 827 customers have overestimated their demand while 623 have underestimated their demand. It is interesting to observe that none of the 827 overestimating customers are selected as target 
Table 3: Types of customers with the wrong calling plans

\begin{tabular}{lllll}
\hline $\begin{array}{l}\text { Current } \\
\text { calling plan }\end{array}$ & $\begin{array}{l}\text { Optimal } \\
\text { calling plan }\end{array}$ & $\begin{array}{l}\text { Number of } \\
\text { customers }\end{array}$ & $\begin{array}{l}\text { Number of } \\
\text { target } \\
\text { customers }\end{array}$ & $\begin{array}{l}\text { Mean } \\
\text { SAVING } \\
\text { (\$) }\end{array}$ \\
\hline General & Premium & 623 & 312 & 5.91 \\
Save & General & 152 & 6 & 3.88 \\
General & Save & 827 & 0 & 2.12 \\
Total & & $\mathbf{1 6 0 2}$ & $\mathbf{3 1 8}$ & $\mathbf{3 . 7 6}$ \\
\hline
\end{tabular}

customers. These customers may not recognise that they are being overcharged because they are light users. Although they recognise the overcharges, they may not want to change because the savings they could make by selecting the 'Save' plan are only $\$ 2.12$ per month on average.

In contrast, about half of the 623 underestimating customers are included in the target group. Actually, 312 out of the 318 target customers are of this type. They can save $\$ 5.91$ a month by switching into the 'Premium' plan, and they are heavy users. They may have complaints about high prices charged by the company. They are likely to move to a competitor unless they are encouraged to switch to the 'Premium' plan.

\section{CONCLUSIONS AND FUTURE RESEARCH}

Managers are very interested in maximising the lifetime values of their customers. A longer planning horizon is required to achieve the goal of developing loyal customers for life. Managers are beginning to understand that they should sacrifice current short-term profits in return for higher retention rates, and the long-term profit maximisation resulting from these higher retention rates. For example, Amazon introduced a customer support service to help customers recognise they are buying the same books. Avid readers frequently search Amazon and buy many books.
Sometimes, however, they do not have time to read the books, and even forget which ones they bought. If Amazon receives a repeat order for a book, it sends a notice explaining to the customer that they purchased the same book with a previous order. Information provided by Amazon allows a customer to change their mind, and review the contents of their bookshelf. As a direct result of this service, Amazon loses a chance of gaining short-term profits. In return, however, it earns strong customer loyalty from those customers leading to even greater long-term profits. Customers should be loyal to Amazon in order to take advantage of this service, since it has their historical purchase records on file. Because of this service, it becomes costly for Amazon customers to switch to other Internet booksellers.

Conceptually, the service provided by Amazon is similar to the marketing strategy of the mobile telecom company. Mobile telecom customers have difficulty understanding the pricing schedules of various calling plans and forecasting their future mobile demand requirements. This often results in their choosing the wrong calling plan. By encouraging such customers to switch to the correct plan and pay less, the company will sacrifice short-term profit, but will increase their long-term profits through increased retention rates.

The marketing strategy discussed in this paper is sustainable. The firm can increase its long-term profits by carefully 
selecting target customers. Also, customers will be more satisfied. They do not need to struggle with the evaluation of alternative calling plans. The firm will analyse historical calling patterns for their customers, and help them make the right decision. If a customer is identified as having selected the wrong calling plan, they are notified and encouraged to select the more appropriate plan.

This paper is now concluded by providing its limitations and the direction of future research. First, it requires several months to determine if a customer has selected the right calling plan. In this paper, the inferred variable SAVING has a measurement error. The company should wait longer to determine the status of customers more accurately. Customers with the wrong calling plan will, however, seek service from competitors if the company waits too long. Secondly, the heterogeneity parameter is not considered in the hazard model used here. For example, the impact of SAVING on the hazard rate may be different across different customers. More sophisticated techniques such as the finite mixture or the Bayesian model can be employed to incorporate unobserved customer heterogeneity in model parameters. ${ }^{12,13}$

\section{Acknowledgment}

This work was supported by the Center for Management Research in the College of Business Administration at Seoul University.

\section{References}

1 Ehrenberg, A. (1972) 'Repeat-buying: Theory and applications', Charles Griffin, Oxford University Press, London.

2 Ehrenberg, A., Goodhardt, G. and Barwise, T. (1990) 'Double jeopardy revisited', Journal of Marketing, Vol. 54, No. 3, pp. 82-91.

3 Reichheld, F. (1996) 'The loyalty effect: The hidden force behind growth, profits, and lasting value', Harvard Business School Press, Boston, MA.

4 Keaveney, S. (1995) 'Consumer switching behavior in service industries: An exploratory study', Journal of Marketing, Vol. 59, pp. 71-82.

5 Jain, D. and Vilcassim, V. (1991) 'Investigating household purchasing timing decisions: A conditional hazard function approach', Marketing Science, Vol. 10, No. 1, pp. 1-23.

6 Gönül, F., Kim, B. and Shi, M. (2000) 'Mailing smarter to catalog customers', Journal of Interactive Marketing, Vol. 14, No. 2, pp. 2-16.

7 Flinn, C. and Heckman, J. (1982) 'Models for the analysis of labor force dynamics', in Rhodes, G. and Basmann, R. (eds) 'Advances in econometrics 1', JAI Press Inc, Greenwich, CT, pp. 35-95.

8 Jain and Vilcassim (1991) op. cit.

9 Schwartz, G. (1978) 'Estimating the dimension of a model', Annals of Statistics, Vol. 6, pp. 461-464.

10 Tuma, N. and Hanna, M. (1984) 'Social dynamics: Models and methods', Academic Press, Inc., Orlando, FL.

11 Allison, P. (1995) 'Survival analysis using the SAS systems: A practical guide', SAS Institute.

12 Rossi, P., McCulloch, R. and Allenby, G. (1996) 'The value of purchase history data in target marketing', Marketing Science, Vol. 15, No. 4, pp. 321-340.

13 Gönül, Kim and Shi (2000) op. cit. 